\title{
Endocan silencing induces programmed cell death in hepatocarcinoma
}

\author{
JINGHUI YANG ${ }^{1}$, SHIHOU SHENG ${ }^{2}$, QIWEI YANG ${ }^{3}$, LI LI $^{4}$, SHAOYOU QIN $^{5}$, SHAN YU $^{6}$ and XUEWEN ZHANG ${ }^{1}$ \\ Departments of ${ }^{1}$ Hepatopancreatobiliary Surgery and ${ }^{2}$ Colorectal \& Anal Surgery, China-Japan Union Hospital, \\ Jilin University, Changchun, Jilin $130033 ;{ }^{3}$ Central Laboratory, Second Hospital, Jilin University, Changchun, \\ Jilin 130041; Departments of ${ }^{4}$ Respiratory Medicine and ${ }^{5}$ Digestive Internal Medicine; ${ }^{6}$ Department of \\ Neurology, China-Japan Union Hospital, Jilin University, Changchun, Jilin 130033, P.R. China
}

Received October 26, 2015; Accepted April 13, 2017

DOI: $10.3892 / \mathrm{ol} .2017 .6857$

\begin{abstract}
Hepatocarcinoma is a type of high-grade malignant carcinoma identified worldwide. Its rapid development and late diagnosis prevents effective tumor resection in the majority of patients, and therefore recent studies have targeted metabolic signaling pathways and the tumor microenvironment for potential treatments. To investigate whether endocan may be a gene target for hepatocarcinoma treatment, the present study employed the following measures: MTT and Transwell assays, flow cytometry, western blotting and an mRFP-GFP-LC3 double fluorescence system. Following endocan gene silencing, cell proliferation was significantly inhibited and the number of invasive cells in the endocan siRNA-treated group was reduced compared with the control-siRNA treated-group. Furthermore, the apoptosis rate was $15 \%$ and autophagy was detected in the endocan short interfering (si)RNA-treated group compared with the control-siRNA treated-group. Using western blotting to detect $\mathrm{NF}-\kappa \mathrm{B}$ expression in the nucleus, the $\mathrm{NF}-\kappa \mathrm{B}$ expression was identified to be significantly reduced in the siRNA-treated group compared with the control groups. Endocan gene silencing inhibited hepatocarcinoma cell viability and invasion, whilst inducing apoptosis and autophagy. The results of the present study suggest that the effect of endocan gene silencing on cell survival was mediated via the $\mathrm{NF}-\kappa \mathrm{B}$ signaling pathway.
\end{abstract}

Correspondence to: Professor Xuewen Zhang, Department of Hepatopancreatobiliary Surgery, China-Japan Union Hospital, Jilin University, 126 Xiantai Street, Changchun, Jilin 130033, P.R. China E-mail: xuewenzhang01@126.com

Dr Shan Yu, Department of Neurology, China-Japan Union Hospital, Jilin University, 126 Xiantai Street, Changchun, Jilin 130033, P.R. China

E-mail: adashan521@sina.com

Key words: hepatocarcinoma, endocan, programmed cell death, apoptosis, autophagy

\section{Introduction}

Hepatocarcinoma is a tumor with a high degree of malignancy. Hepatocarcinoma is the second most prevalent cause of cancer-associated mortality in males and the sixth leading cause in female patients (1). Typically, treatment for hepatocarcinoma is not administered in a timely manner due to late diagnosis. The majority of patients are diagnosed when effective surgery is not possible and in other patients, metastases are identified during surgery. Therefore patient prognosis is typically poor (2). Increasing attention has focused on identifying efficient therapeutic targets for hepatocarcinoma treatment.

Endocan expression has been reported in numerous types of tumor and therefore may represent a target for carcinoma treatment (3-8). In particular, endocan is overexpressed in tumor cells where it promotes tumor growth (9). In addition, the circulating levels of endocan increase over time and have been positively correlated with tumor size (9). Endocan was identified to be significantly overexpressed in endothelial cells isolated from hepatocellular carcinoma tissue compared with corresponding non-cancerous liver tissue (10). Endocan is also expressed at the periphery of tumor cells in hepatocellular carcinoma tissue (11). Furthermore, the mRNA expression of endocan in tissue samples has been associated with the tumor node metastasis stage, tumor vascular invasion and metastasis in patients with hepatocarcinoma (11). Further studies have demonstrated that the endocan expression in tumors is associated with their angiogenic and invasive properties $(12,13)$. In vascular endothelial cells, certain factors promote the expression of endocan, including cultured hepatocyte growth factors, scatter factors, fibroblast growth factor-2 and vascular endothelial growth factor (14).

In the present study, endocan silencing experiments were performed using small interfering (si)RNA. In particular, cell proliferation and invasion were examined following endocan siRNA treatment in SK-HEP-1 cells, and cell survival was evaluated using flow cytometry and western blot analysis.

\section{Materials and methods}

Cell culture. Human SK-HEP-1 hepatocarcinoma cells were obtained from the American Type Culture Collection 
(Manassas, VA, USA). Cells were cultured in minimal essential medium (Gibco; Thermo Fisher Scientific, Inc., Waltham, MA, USA) containing $10 \%$ fetal bovine serum (FBS; Hyclone; GE Healthcare Life Sciences, Logan, UT, USA). All cells were incubated at $37^{\circ} \mathrm{C}$ in an atmosphere containing $5 \% \mathrm{CO}_{2}$. The inoculum size was $3 \times 10^{3}$ cells/well in a 96 -multiwell plate, $2 \times 10^{4}$ cells/well in a 24 -multiwell plate or $3 \times 10^{5}$ cells/well in a 6-multiwell plate (BD Biosciences, Franklin Lakes, NJ, USA). The medium was replaced every 2 days. The dose of pyrrolidine dithiocarbamate (PDTC) was $10 \mu \mathrm{M}$ and the duration of treatment was $24 \mathrm{~h}$ at $37^{\circ} \mathrm{C}$. The controls used dimethyl sulfoxide (DMSO).

SiRNA knockdown of endocan gene expression of human SK-HEP-1 hepatocarcinoma cells. In 6-well plates, $8 \mu 1$ Lipofectamine $2000^{\circledR}$ (Thermo Fisher Scientific, Inc.). $+2 \mu \mathrm{g}$ pRNA-H1.1+2 $\times 10^{6}$ cells ( $70-80 \%$ confluence) were placed in every well. Endocan-targeting and control siRNAs (5'-TTC TCCGAACGTGTCACGT-3') were purchased from Sangon Biotech Co., Ltd. (Shanghai, China). pRNA-H1.1 plasmids were constructed and used as the siRNA vector according to the protocol of the manufacturer (Jinsirui Science and Technology Biology Corp., Nanjing, China), and it was transfected into cells using Lipofectamine $2000^{\circledR}$. The plasmid connection system contains 0.03 pmol pRNA-H1.1, $20 \mathrm{nmol}$ Insert DNA, $2.5 \mu 1$ 10xT4 DNA Ligase Buffer, $1 \mu 1$ T4 DNA Ligase and $\mathrm{ddH}_{2} \mathrm{O}$ up to $25 \mu \mathrm{l}$. The target sequence of endocan was 5'-GGTCTCCCGTAATGAGGAA-3'. A total of $2 \mu \mathrm{g}$ siRNA vector was used to transfect into SK-HEP-1 cells with Lipofectamine 2000 kit (Invitrogen; Thermo Fisher Scientific, Inc.) according to the manufacturer's protocol.

Western blot analysis. Western blotting was performed $48 \mathrm{~h}$ following transfection. SDS-PAGE (Bio-Rad Laboratories, Inc., Hercules, CA, USA) was conducted using 10 and $14 \%$ gels, according to the manufacturer's protocol. Protein extraction was performed with $2 \mathrm{ml}$ radioimmunoprecipitation lysate (Beyotime Institute of Biotechnology, Haimen, China) on ice for $5 \mathrm{~min}$. Centrifugation was performed at $24,000 \mathrm{x} \mathrm{g}$ and $4^{\circ} \mathrm{C}$ for $10 \mathrm{~min}$. The protein quantification method used was BCA, $200 \mu \mathrm{l}$ of BCA at $37^{\circ} \mathrm{C}$ for $20 \mathrm{~min}$. A total of $40 \mu \mathrm{g}$ protein was loaded per lane. Proteins were transferred onto polyvinylidene difluoride membranes. The membrane was blocked in a solution of TBS-Tween 20 containing 5\% non-fat dry milk for $1 \mathrm{~h}$ at $25^{\circ} \mathrm{C}$ with constant agitation. Proteins were probed with a number of primary antibodies (Santa Cruz Biotechnology, Inc., Dallas, TX, USA). The primary antibodies were as follows: Endocan antibody (sc-515304; Santa Cruz Biotechnology, Inc.; 1:200) at $4^{\circ} \mathrm{C}$ overnight; LC3 antibody (AL221; Beyotime Institute of Biotechnology; 1:500) at $4^{\circ} \mathrm{C}$ overnight; ATG5 antibody (PA2260; Boster Biological Technology, Pleasanton, CA, USA; $1: 400$, ) at $4^{\circ} \mathrm{C}$ overnight; ATG7 antibody (PB9479; Boster Biological Technology; 1:400) at $4^{\circ} \mathrm{C}$ overnight; DRAM antibody (bs-4233R, BIOSS, Beijing, China; 1:500) at $4^{\circ} \mathrm{C}$ overnight; Beclin-1 antibody (AB123; Beyotime Institute of Biotechnology; 1:1,000) at $4^{\circ} \mathrm{C}$ overnight and NF- $\mathrm{BB}$ p65 antibody (AF0246; Beyotime Institute of Biotechnology; $1: 1,000)$ at $4^{\circ} \mathrm{C}$ overnight. The membranes were incubated with secondary horseradish peroxidase-conjugated anti-Immunoglobulin G antibody (A0181; Beyotime Institute of Biotechnology; $1: 5,000$ ) at $37^{\circ} \mathrm{C}$ for $45 \mathrm{~min}$. $\beta$-actin was used as a loading control. Immunolabeled proteins were detected following incubation with ECL substrate (Beyotime Institute of Biotechnology) at room temperature for $50 \mathrm{sec}$, followed by exposure of the membrane to autoradiographic film. Density analysis was performed using a Gel Doc system (Gel Doc XR+; Bio-Rad Laboratories, Inc.). The nucleus protein and cell plasma protein extraction kit (P0028, contain reagent A and reagent B) was purchased from Beyotime Institute of Biotechnology and used to separate the cytoplasm and nuclear fractions. Reagent A digested the cell membrane and Reagent $\mathrm{B}$ digested the cell nucleus.

Cell viability measured using an MTT assay. Following varying durations following transfection $(24,48,72$ or $96 \mathrm{~h})$, the culture medium was replaced with a medium containing $5 \mathrm{mg} / \mathrm{ml}$ MTT (Sigma-Aldrich; Merck KGaA, Darmstadt, Germany), and the cells were incubated for $24 \mathrm{~h}$ at $37^{\circ} \mathrm{C}$. The supernatant was discarded and DMSO was used to dissolve the purple crystals. The absorbance at a wavelength of $490 \mathrm{~nm}$ was measured using a microplate reader (BioTek Instruments, Inc., Winooski, VT, USA).

Cell invasion assays. After 48-h of endocan siRNA treatment in Dulbecco's modified Eagle medium (DMEM; Gibco; Thermo Fisher Scientific, Inc.) containing 10\% FBS, the SK-HEP-1 cells were harvested $(24,000 \mathrm{x}$ g for $5 \mathrm{~min}$ at room temperature) using trypsin. Then the cells were washed in DMEM with a soybean trypsin inhibitor and without serum. The cells were suspended in serum-free DMEM at a density of $1 \times 10^{5}$ cells $/ \mathrm{ml}$. Matrigel (BD Biosciences) was put into Transwell. The cells $\left(2 \times 10^{4} /\right.$ well $)$ were allowed to migrate towards DMEM containing 20\% FBS in the bottom chamber of the Transwell. The 24-well plates were incubated for $24 \mathrm{~h}$ at $37^{\circ} \mathrm{C}$. The invaded cells on the bottom surface of the membrane were stained with crystal violet at room temperature for $5 \mathrm{~min}$. The number of migrated cells was counted in 5 randomly selected fields using a light microscope at a magnification of $x 200$. Data presented are representative of the average of 3 individual wells.

Apoptosis detection using flow cytometry. The SK-HEP-1 cells were cultured for $48 \mathrm{~h}$ following treatment with endocan siRNA in DMEM containing 10\% FBS. The cells were harvested (24,000 x g for $5 \mathrm{~min}$ at room temperature) by trypsinization and washed in DMEM with a soybean trypsin inhibitor and without serum. The cells were suspended in $500 \mu \mathrm{l}$ of binding buffer (556547; BD Biosciences), and $5 \mu 1$ Annexin V-FITC was added, together with $5 \mu \mathrm{l}$ propidium iodide. The cells ware incubated for $15 \mathrm{~min}$. The flow cytometer and software (WinMDI v2.8) used was FACSCalibur (BD Biosciences).

mRFP-GFP-LC3 fluorescence system assays. Following the appropriate cell culture period (density $80 \%$ ), adenovirus infection was performed according to the manufacturer's protocol (mRFP-GFP-LC3; Hanbio, Shanghai, China; adenovirus number: cell number, 15:1). The plates were incubated for $4 \mathrm{~h}$ at $37^{\circ} \mathrm{C}$ with $5 \% \mathrm{CO}_{2}$ in a humidified atmosphere. Stationary infected cells, or those cells that were able to stably present fluorescent signals, were incubated in $4 \%$ paraformaldehyde 
A

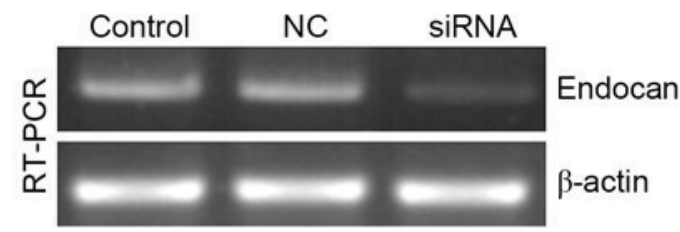

B

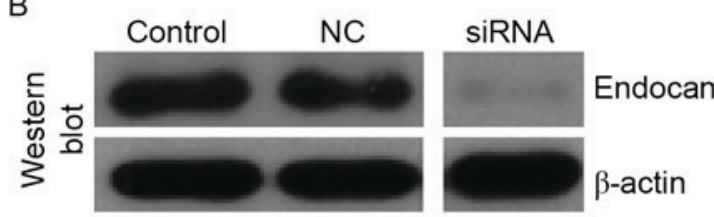

C

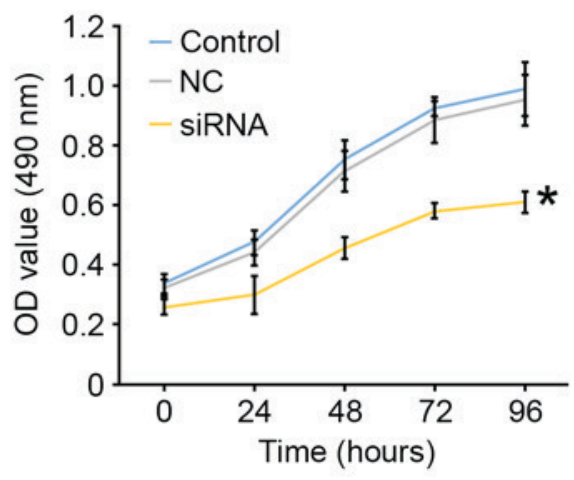

$\mathrm{D}$
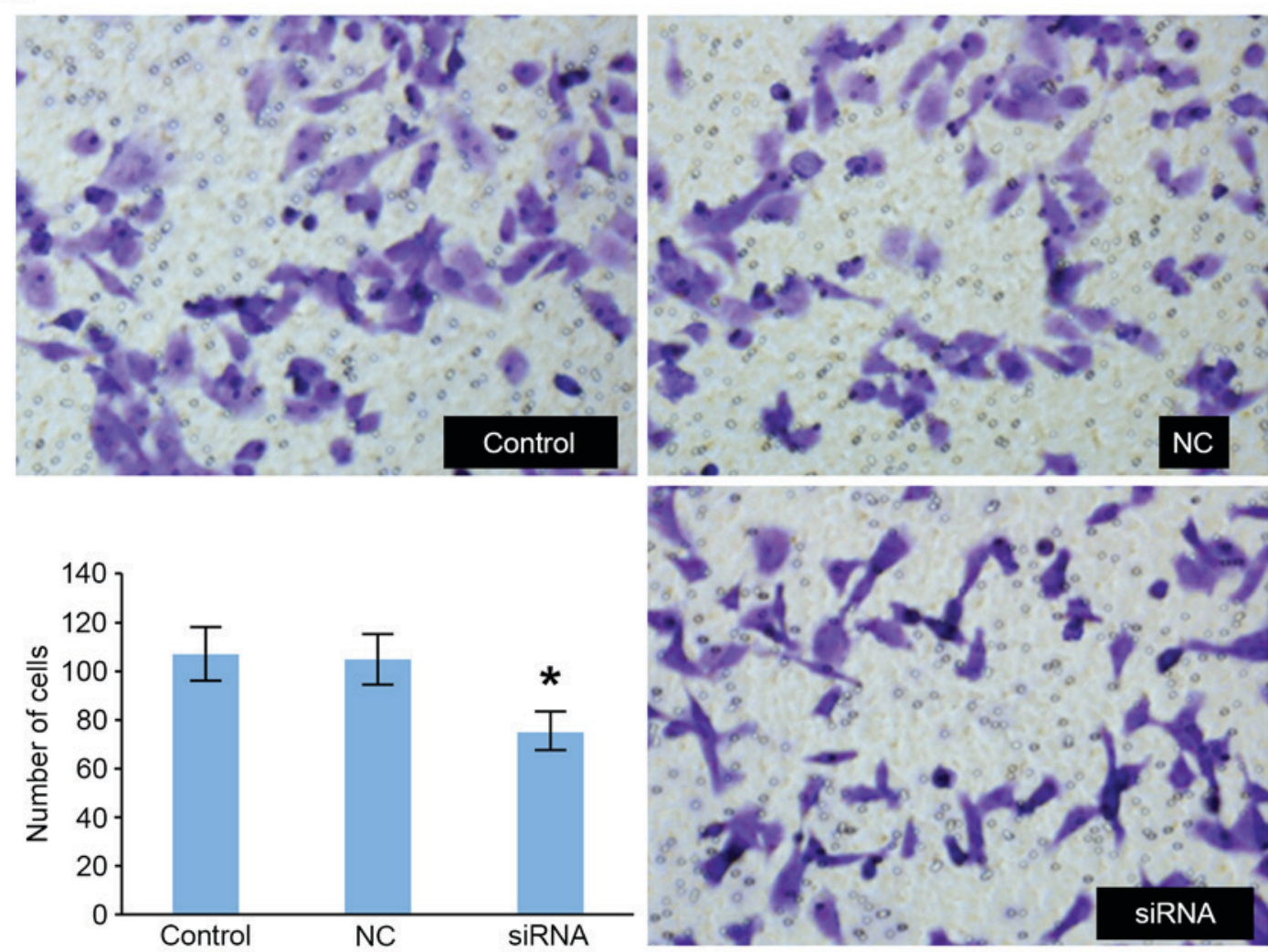

Figure 1. Endocan siRNA and NC siRNA constructs were transfected in SK-HEP-1 cells. siRNA against endocan suppressed its expression, evaluated using (A) RT-PCR and (B) western blotting (normalized to $\beta$-actin). (C) SK-HEP-1 cells cultured in 96-well plates were transfected with endocan siRNA, and cells were analyzed $0,24,48,72$ and $96 \mathrm{~h}$ following transfection. The cell proliferation was determined with an MTT assay. Data were presented as the mean \pm standard deviation $(n=3)$. The average OD value from each sample was obtained from 5 replicates. (D) Transwell assays were used to investigate the migratory and invasive abilities of the control, $\mathrm{NC}$ and siRNA groups. Invading cells were stained with crystal violet and counted in $\geq 5$ fields using a light microscope (magnification, $x 200)$. * $\mathrm{P}<0.05$ in siRNA groups vs. NC groups. OD, optical density; NC, negative control; siRNA, small interfering RNA; RT-PCR, reverse transcription polymerase chain reaction.

for $0.5 \mathrm{~h}$ at $4^{\circ} \mathrm{C}$. The level of fluorescence in the cells was observed using a fluorescence microscope. Cells in every 5 fields of view were counted.

Reverse transcription-quantitative polymerase chain reaction (RT-qPCR). RNA extraction buffer was purchased from BioTek Instruments, Inc. (RP5611). TIANScript RT kit (KR104) was supplied by Tiangen Biotech Co., Ltd. (Beijing, China). The primer sequences were as follows: Endocan forward, 5'-CTG GGAAACATGAAGAGCG-3' and reverse, 5'-GCCTGAGAC TGTGCGGTAG-3' and $\beta$-actin forward, 5'-CTTAGTTGC GTTACACCCTTTCTTG-3' and reverse, 5'-CTGTCACCT
TCACCGTTCCAGTTT-3'. The fluorophore used Gold View (Beijing Solarbio Science and Technology, Co., Ltd, Beijing, China). The RT reaction was performed with $1 \mu$ l oligo (dT)15, $1 \mu \mathrm{l}$ random primer, $2 \mu \mathrm{l} \mathrm{dNTP}$ (2.5 mM each), $10.5 \mu \mathrm{l}$ $\mathrm{ddH}_{2} \mathrm{O}(2)$, and the thermocycler conditions were as follows: $70^{\circ} \mathrm{C}$ for $5 \mathrm{~min}$, cooling on ice for $2 \mathrm{~min}$, and then $4 \mu \mathrm{l} 5 \mathrm{X}$ First-Strand Buffer, $0.5 \mu \mathrm{l}$ RNasin, $1 \mu \mathrm{l}$ (200 U) TIANScript M-MLV were placed in each tube at $42^{\circ} \mathrm{C}$ for $50 \mathrm{~min}$, then at $95^{\circ} \mathrm{C}$ for $5 \mathrm{~min}$. The thermocycler conditions were: $95^{\circ} \mathrm{C}$ for $5 \mathrm{~min}, 95^{\circ} \mathrm{C}$ for $20 \mathrm{sec}, 52^{\circ} \mathrm{C}$ for $20 \mathrm{sec}, 72^{\circ} \mathrm{C}$ for $30 \mathrm{sec}$ for 40 cycles. The experiment was repeated 3 times. The method of quantification was gel electrophoresis, using $1.5 \%$ sepharose 
gel. The gel mixture was heated in the microwave oven until boiling. When cooled to $50-60^{\circ} \mathrm{C}$, Gold View (Beyotime Institute of Biotechnology, Shanghai, China) dye (0.01\%) was blended. The DNA ladder was purchased from Beyotime Institute of Biotechnology.

$N F-\kappa B$ inhibitor treatment. Cell cultures were performed as aforementioned. The four groups prepared as follows: the $\mathrm{NC}+$ DMSO group, siRNA + DMSO group, NC + PDTC group, siRNA + PDTC group. DMSO and $10 \mu \mathrm{M} \mathrm{NF- \kappa B}$ pathway inhibitor ammonium PDTC (Beyotime Institute of Biotechnology) were added to the culture for $24 \mathrm{~h}$ at room temperature.

Statistical analysis. Data were assessed using the Student's t-test or one-way analysis of variance, as appropriate, followed by the Turkey's post-hoc test. All statistics were calculated using SPSS software (version 17.0; SPSS Inc., Chicago, IL, USA). $\mathrm{P}<0.05$ was considered to indicate a statistically significant difference. Data are presented as the mean \pm standard deviation. The number of replications was three.

\section{Results}

Gene silencing of endocan decreases cell proliferation and cell invasion. In the present study, SK-HEP-1 cells treated with endocan siRNA were monitored for cell proliferation and invasion using an MTT and a Transwell assay, respectively. The following 3 groups were established: Untreated control; negative control (NC) siRNA; and endocan siRNA groups. To determine siRNA efficiency, the endocan mRNA transcript and protein level were evaluated using RT-PCR and western blotting, respectively (Fig. 1A and B). The level of endocan expression was decreased in the endocan siRNA compared with the NC and control groups (Fig. 1A and B). Cell proliferation was evaluated using the MTT assay and was significantly reduced in siRNA-treated cells compared with the two control groups (Fig. 1C). In the Transwell assay, the invasive ability of endocan siRNA-treated cells was significantly reduced compared with the NC and control groups (Fig. 1D).

Gene silencing of endocan enhances apoptosis in SK-HEP-1 cells. The apoptosis assay demonstrated that endocan silencing resulted in a marked increase in the apoptosis rate (Fig. 2). Overall, these results suggest that endocan silencing promotes cell apoptosis.

Gene silencing of endocan enhances autophagy in SK-HEP-I cells. To determine whether the gene silencing of endocan is able to induce autophagy, autophagy-associated protein expression levels were evaluated using western blotting (Fig. 3A). The expression levels of microtubule associated protein 1 light chain $3 \alpha$ (LC3), autophagy related (ATG)5, ATG7, DNA damage regulated autophagy modulator 1 (DRAM) and Beclin-1 protein following transfection with endocan siRNA were significantly increased compared with those of the NC, and control groups (Fig. 3B). These results suggest that endocan silencing promotes autophagy in hepatocarcinoma cells. In Fig. 4A, no increased level red fluorescence was observed compared with in Fig. 4B or C. In Fig. 4B, an increased level
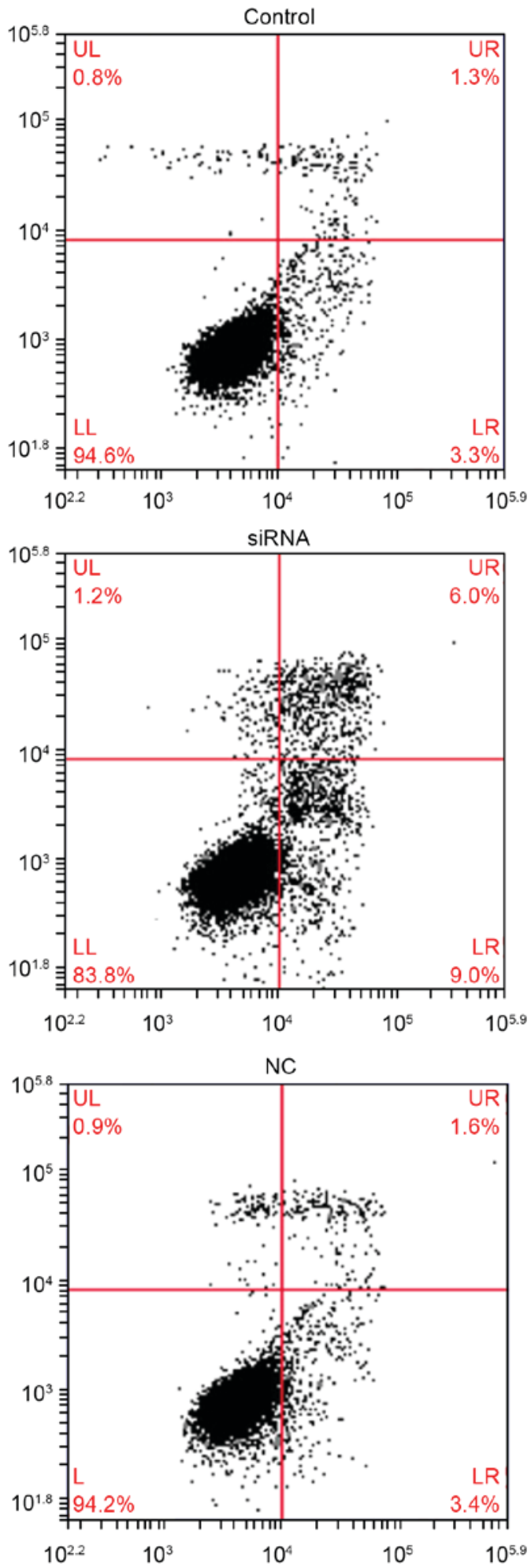

Figure 2. Endocan silencing increases the apoptosis rate compared with NC siRNA treated and control cells. UR+LR quadrants represent apoptotic cells and were included in the apoptosis rate. The horizontal axes represent positive Annexin V-fluorescein isothiocyanate. The vertical axis represents positive propidium iodide. UL, upper left; UR, upper right; LL, lower left; LR, lower right; NC, negative control; siRNA, small interfering RNA.

red fluorescence was observed compared with in Fig. 4A or C, this revealed that there was an increased level of autophagy in Fig. 4B. In Fig. 4C, no increased level red fluorescence was observed compared with in Fig. $4 \mathrm{~A}$ or B. 


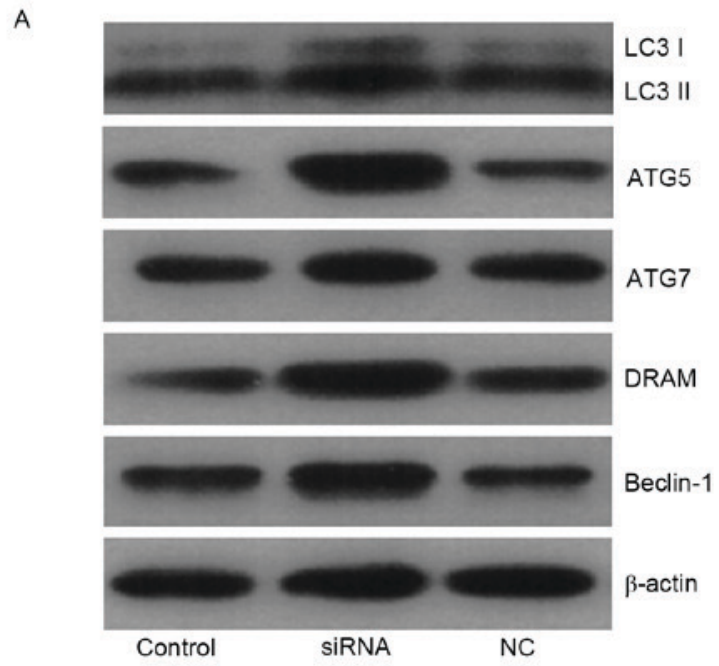

B
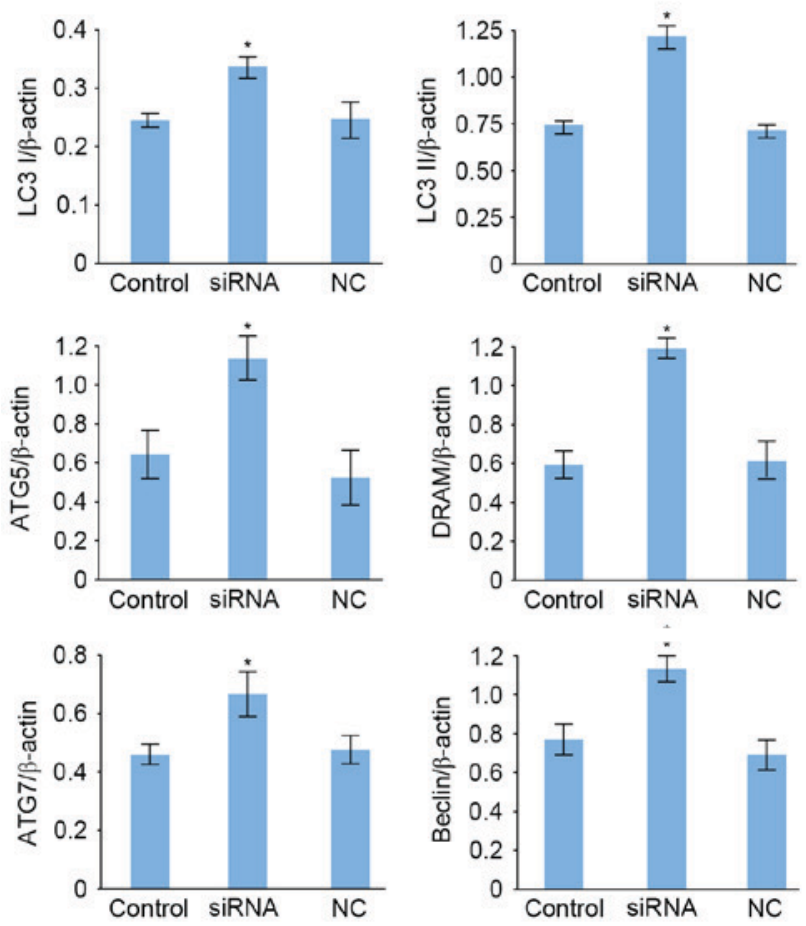

Figure 3. The levels of LC3, ATG5, ATG7, DRAM and Beclin-1 protein expression were measured following transfection with endocan siRNA and normalized to $\beta$-actin. (A) Representative blot and (B) quantification of autophagy-associated protein expression. The expression levels of all the autophagy-associated proteins were significantly increased in endocan siRNA-treated cells compared with those in the NC and control groups. ${ }^{*} \mathrm{P}<0.05$ in siRNA groups vs. NC groups. NC, negative control; siRNA, small interfering RNA; LC3, microtubule associated protein 1 light chain $3 \alpha$; ATG, autophagy related; DRAM, DNA damage regulated autophagy modulator 1 .

Association between endocan gene expression and the nuclear factor $(N F)-\kappa B$ signaling pathway. To determine whether the gene silencing of endocan is able to influence the $\mathrm{NF}-\kappa \mathrm{B}$ signaling pathway, $\mathrm{NF}-\kappa \mathrm{B}$ p 65 protein expression was evaluated using western blotting (Fig. 5A). The level of $\mathrm{NF}-\kappa \mathrm{B}$ p 65 protein within the nucleus following transfection with endocan siRNA was significantly reduced compared with that of the cells in the NC and control groups (Fig. 5A and B). Furthermore, the level of endocan protein was significantly reduced following treatment with $\mathrm{NF}-\kappa \mathrm{B}$ pathway inhibitor
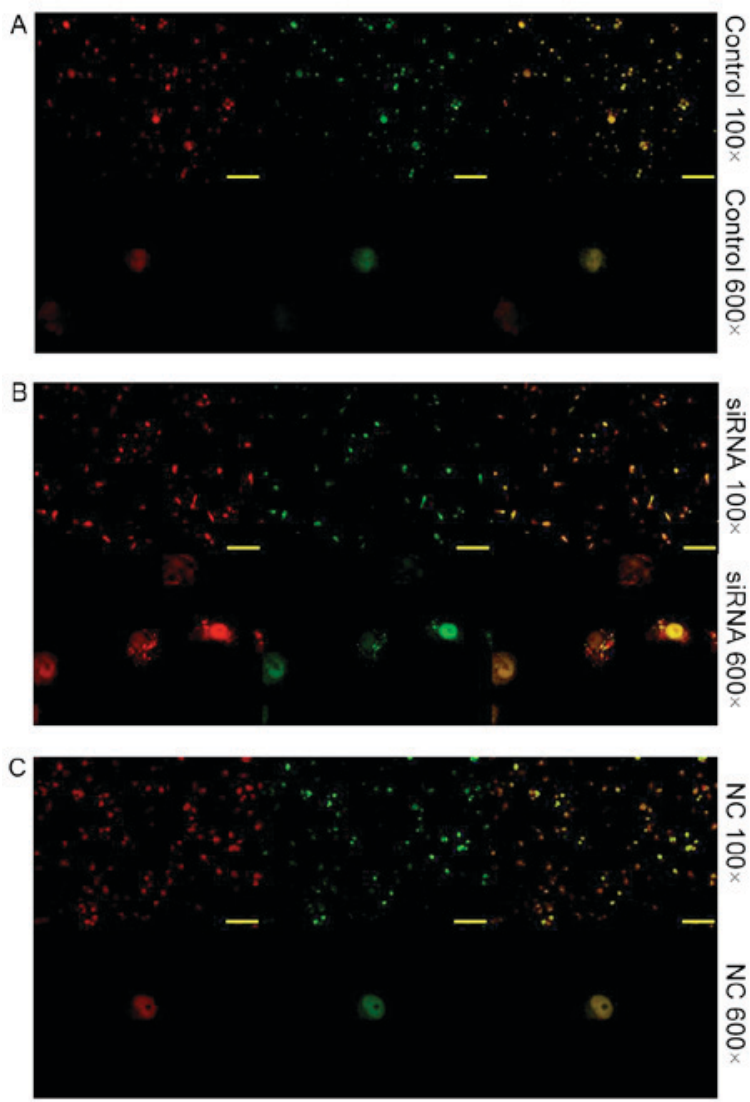

Figure 4. Autophagy was detected using the mRFP-GFP-LC3 system. Red fluorescence, lysosomes; green fluorescence, autophagosome. mRFP-GFP-LC3 was transfected into cells of the (A) control, (B) endocan-targeting siRNA and (C) NC siRNA groups, and after $48 \mathrm{~h}$ expression was analyzed using fluorescence microscopy (magnification, x100 or x600). The mRFP-GFP-LC3 microtubule associated protein 1 light chain $3 \alpha$ foci were monitored. Yellow fluorescence is the result of merging the red and green fluorescence images. Green fluorescent foci are observed to reduce alongside the formation of the autophagic lysosome. NC, negative control; siRNA, small interfering RNA. Scale bar $=10 \mu \mathrm{m}$.

ammonium PDTC (Fig. 5C and D) compared with DMSO. These results demonstrated the synergistic effects of endocan gene expression on the NF- $\kappa \mathrm{B}$ signaling pathway. The expression level of the endocan protein were as follows: $\mathrm{NC}+\mathrm{DMSO}$ group $>$ siRNA+DMSO group; siRNA+DMSO group $>$ siRNA+PDTC group; NC+PDTC group $>$ siRNA+PDTC group.

\section{Discussion}

Effective tumor treatment remains a challenge for clinicians and researchers. There are currently 2 types of non-surgical therapy for hepatocarcinoma; One therapy targets the tumor and the other targets the tumor microenvironment. Previous studies have demonstrated that endocan may represent a target for tumor-targeted therapy (3-8). Although there is insufficient data regarding whether endocan may be an effective tumor marker similar to $\alpha$-fetoprotein, a number of previous studies have reported that endocan is associated with tumor cell survival $(9,10,12,14)$. Indeed, endocan gene silencing was utilized to inhibit tumor cell survival in human colon carcinoma (14), concordant with the results of the present study. Using MTT and Transwell assays, the results of the current 


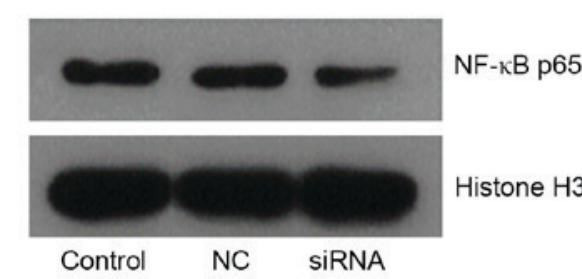

C

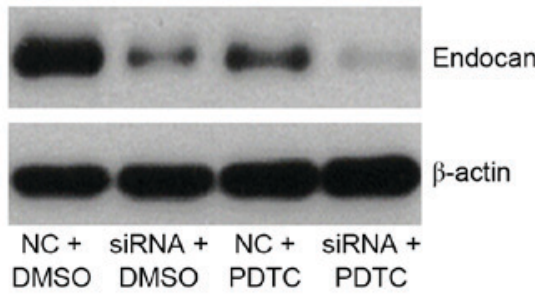

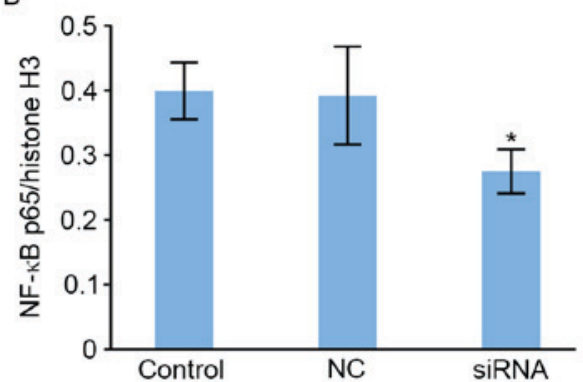

D

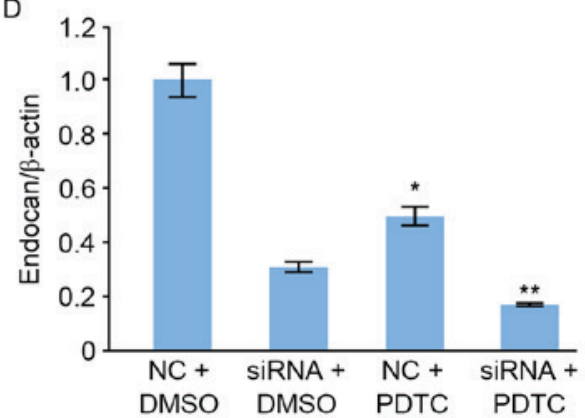

Figure 5. The expression of NF-kB p65 protein within the nucleus was measured using western blotting following transfection with endocan siRNA. (A) Representative blot and (B) quantification of NF- $\mathrm{BB}$ p65 expression. The expression was significantly reduced in endocan siRNA-treated cells compared with cells in the NC and control groups. "P $<0.05$ on siRNA groups vs. NC groups. (C) The cells were incubated with $10 \mu \mathrm{M}$ PDTC and an equal volume of DMSO, and then the level of endocan protein was determined. (D) Quantification of endocan protein expression. ${ }^{*}<<0.05, \mathrm{NC}+\mathrm{PDTC}$ vs. NC+DMSO; ${ }^{* *} \mathrm{P}<0.05$, siRNA+PDTC vs. NC+DMSO or siRNA+DMSO. NC, negative control; siRNA, small interfering RNA; PDTC, ammonium pyrrolidine dithiocarbamate; $\mathrm{NF}-\kappa \mathrm{B}$, nuclear factor- $\kappa \mathrm{B}$.

study further demonstrate that endocan silencing inhibits SK-HEP-1 cell proliferation and invasion, which indicates that endocan may serve as a treatment target in hepatocarcinoma.

The induction of programmed cell death (PCD) is the preferred result for tumor treatment. Specifically, tumor-cell PCD may be targeted without injuring healthy cells. Apoptosis represents type I PCD and involves a series of morphological and biochemical processes, including alterations in the mitochondrial membrane potential, opening of mitochondrial pores, phosphoserine shifts and the gathering of nuclearchromatin(15). An Annexin V-FITC kit was used with flow cytometry analysis to determine alterations in apoptotic rates, and the results identified that apoptosis was induced in siRNA-treated SK-HEP-1 cells. The low apoptotic cell ratio may be due to the short observation time; therefore, if the observation time had been extended, the ratio may have increased. Autophagy serves an important role in cell survival and death, and a certain degree of autophagy occurs during normal cellular metabolism. The purpose of autophagy is to digest metabolic waste or remove misfolded proteins. Furthermore, autophagy leads to cell death, specifically type II PCD (16). Through autophagy-associated protein determination, evidence of autophagy was observed in endocan siRNA-treated cells. The autophagy-associated proteins investigated include LC3 (17,18), ATG5 (19), ATG7, Beclin-1 (20) and DRAM (21). The significant increase in the expression of these proteins in siRNA-treated cells compared with $\mathrm{NC}$ and control cells indicate the increased level of autophagy in the endocan siRNA-treated cells. Furthermore, red and green fluorescent dyes were used for the detection of LC3, as observed through the lack of green fluorescence due to the formation of autophagic lysosomes, it is suggested that endocan silencing induces autophagy.
$\mathrm{NF}-\mathrm{kB}$ serves an important role in cell survival and this transcription factor may be phosphorylated to regulate gene expression in the nucleus $(22,23)$. NF- $\mathrm{\kappa B}$ is also an important regulator of gene promoters. In the process of cell apoptosis, $\mathrm{NF}-\kappa \mathrm{B}$ may regulate the function of apoptotic proteins $(24,25)$, anti-apoptotic proteins (26-28) and tumor-suppressor proteins (29-31). To investigate the underlying mechanism of endocan gene silencing in hepatocarcinoma cell apoptosis and autophagy, the NF- $\mathrm{BB}$ signaling pathway was used as an indicator. In the current study, it was demonstrated that following endocan gene silencing, NF- $\kappa \mathrm{B}$ expression decreased significantly in the cell nucleus compared with $\mathrm{NC}$ and control cells that were not treated with endocan siRNA, which may have contributed to the impaired survival of hepatocarcinoma cells. In addition, the influence of the NF- $\mathrm{KB}$ signaling pathway on endocan expression was demonstrated as following inhibition of the NF- $\mathrm{kB}$ signaling pathway through treatment of cells with PDTC, endocan expression was significantly decreased compared with untreated cells.

In conclusion, the results of the present study demonstrated that endocan silencing induced PCD in SK-HEP-1 cells. Thus, endocan may be a treatment target for hepatocarcinoma. Furthermore, these results identified an association between endocan gene expression and the NF- $\kappa \mathrm{B}$ signaling pathway, suggesting that combined treatments may improve the efficiency of inhibiting hepatocarcinoma progression.

\section{Acknowledgements}

The authors would like to thank Dr Xihe Yu for technical support and the China-Japan Union Hospital (Changchun, China) for its support. 


\section{References}

1. Torre LA, Bray F, Siegel RL, Ferlay J, Lortet-Tieulent J and Jemal A: Global cancer statistics, 2012. CA Cancer J Clin 65 : 87-108, 2015.

2. Song MJ and Bae SH: Newer treatments for advanced hepatocellular carcinoma. Korean J Intern Med 29: 149-155, 2014.

3. Abid MR, Yi XJ, Yano K, Shih SC and Aird WC: Vascular endocan is preferentially expressed in tumor endothelium. Microvasc Res 72: 136-145, 2006.

4. Maurage CA, Adam E, Minéo JF, Sarrazin S, Debunne M, Siminski RM, Baroncini M, Lassalle P, Blond S and Delehedde M: Endocan expression and localization in human glioblastomas. J Neuropathol Exp Neurol 68: 633-641, 2009.

5. Ziol M, Sutton A, Calderaro J, Barget N, Aout M, Leroy V, Blanc JF, Sturm N, Bioulac-Sage P, Nahon P, et al: ESM-1 expression in stromal cells is predictive of recurrence after radiofrequency ablation in early hepatocellular carcinoma. J Hepatol 59: 1264-1270, 2013.

6. Oltean S, Pullerits R, Flodén A, Olausson M and Oltean M: Increased resistin in brain dead organ donors is associated with delayed graft function after kidney transplantation. J Transl Med 11: 233, 2013.

7. Leroy X, Aubert S, Zini L, Franquet H, Kervoaze G, Villers A, Delehedde M, Copin MC and Lassalle P: Vascular endocan (ESM-1) is markedly overexpressed in clear cell renal cell carcinoma. Histopathology 56: 180-187, 2010.

8. Zuo L, Zhang SM, Hu RL, Zhu HQ, Zhou Q, Gui SY, Wu Q and Wang Y: Correlation between expression and differentiation of endocan in colorectal cancer. World J Gastroenterol 14: 4562-4568, 2008.

9. Scherpereel A, Gentina T, Grigoriu B, Sénéchal S, Janin A, Tsicopoulos A, Plénat F, Béchard D, Tonnel AB and Lassalle P: Overexpression of endocan induces tumor formation. Cancer Res 63: 6084-6089, 2003.

10. Kang YH, Ji NY, Lee CI, Lee HG, Kim JW, Yeom YI, Kim DG, Yoon SK, Kim JW, Park PJ and Song EY: ESM-1 silencing decreased cell survival, migration, and invasion and modulated cell cycle progression in hepatocellular carcinoma. Amino Acids 40: 1003-1013, 2011.

11. Chen LY, Liu X, Wang SL and Qin CY: Over-expression of the Endocan gene in endothelial cells from hepatocellular carcinoma is associated with angiogenesis and tumour invasion. J Int Med Res 38: 498-510, 2010.

12. Huang GW, Tao YM and Ding X: Endocan expression correlated with poor survival in human hepatocellular carcinoma. Dig Dis Sci 54: 389-394, 2009

13. Gerritsen ME, Tomlinson JE, Zlot C, Ziman M and Hwang S: Using gene expression profiling to identify the molecular basis of the synergistic actions of hepatocyte growth factor and vascular endothelial growth factor in human endothelial cells. Br J Pharmacol 140: 595-610, 2003.

14. Kim JH, Park MY, Kim CN, Kim KH, Kang HB, Kim KD and Kim JW: Expression of endothelial cell-specific molecule-1 regulated by hypoxia inducible factor- $1 \alpha$ in human colon carcinoma: Impact of ESM-1 on prognosis and its correlation with clinicopathological features. Oncol Rep 28: 1701-1708, 2012 .
15. Kepp O, Galluzzi L, Lipinski M, Yuan J and Kroemer G: Cell death assays for drug discovery. Nat Rev Drug Discov 10: 221-237, 2011.

16. Jardon MA, Rothe K, Bortnik S, Vezenkov L, Jiang X, Young RN, Lum JJ and Gorski SM: Autophagy: From structure to metabolism to therapeutic regulation. Autophagy 9: 2180-2182, 2013.

17. Huang R and Liu W: Identifying an essential role of nuclear LC3 for autophagy. Autophagy 11: 852-853, 2015.

18. Lai SC and Devenish RJ: LC3-associated phagocytosis (LAP): Connections with host autophagy. Cells 1: 396-408, 2012.

19. Codogno P and Meijer AJ: Atg5: More than an autophagy factor. Nat Cell Biol 8: 1045-1047, 2006.

20. Huang X, Qi Q, Hua X, Li X, Zhang W, Sun H, Li S, Wang X and Li B: Beclin 1, an autophagy-related gene, augments apoptosis in U87 glioblastoma cells. Oncology Rep 31: 1761-1767, 2014.

21. Criollo A, Dessen P and Kroemer G: DRAM: A phylogenetically ancient regulator of autophagy. Cell Cycle 8: 2319-2320, 2009.

22. Hu X, Nesic-Taylor O, Qiu J, Rea HC, Fabian R, Rassin DK and Perez-Polo JR: Activation of nuclear factor-kappaB signaling pathway by interleukin-1 after hypoxia/ischemia in neonatal rat hippocampus and cortex. J Neurochem 93: 26-37, 2005.

23. Karin M, Yamamoto Y and Wang QM: The IKK NF-kappa B system: A treasure trove for drug development. Nat Rev Drug Discov 3: 17-26, 2004

24. Tato CM and Hunter CA: Host-pathogen interactions: Subversion and utilization of the NF-kappa B pathway during infection. Infect Immun 70: 3311-3317, 2002

25. Bai X, Feldman NE, Chmura K, Ovrutsky AR, Su WL, Griffin L, Pyeon D, McGibney MT, Strand MJ, Numata M, et al: Inhibition of nuclear factor-kappa B activation decreases survival of Mycobacterium tuberculosis in human macrophages. PLoS One 8: e61925, 2013.

26. Loeuillet C, Martinon F, Perez C, Munoz M, Thome M and Meylan PR: Mycobacterium tuberculosis subverts innate immunity to evade specific effectors. J Immunol 177: 6245-6255, 2006.

27. Karin M, Cao Y, Greten FR and Li ZW: NF-kappaB in cancer: From innocent bystander to major culprit. Nat Rev Cancer 2: 301-310, 2002.

28. Fukuda M, Kusama K and Sakashita H: Cimetidine inhibits salivary gland tumor cell adhesion to neural cells and induces apoptosis by blocking NCAM expression. BMC Cancer 8: 376 , 2008.

29. Djavaheri-Mergny M, Amelotti M, Mathieu J, Besançon F, Bauvy C, Souquère S, Pierron G and Codogno P: NF-kappaB activation represses tumor necrosis factor-alpha-induced autophagy. J Biol Chem 281: 30373-30382, 2006.

30. Peri S, Devarajan K, Yang DH, Knudson AG and Balachandran S: Meta-analysis identifies NF- $\kappa \mathrm{B}$ as a therapeutic target in renal cancer. PLoS One 8: e76746, 2013.

31. Orlowski RZ and Baldwin AS Jr: NF-kappaB as a therapeutic target in cancer. Trends Mol Med 8: 385-389, 2002. 